\title{
MUTACIONES DEL GEN DEL RECEPTOR DE ANDRÓGENOS EN PACIENTES CON ADENOCARCINOMA DE PRÓSTATA CLÍNICAMENTE LOCALIZADO
}

\author{
D. SÁNCHEZ ZALABARDO, D. ROSELL COSTA, B. HONORATO CIA*, J. RIOJA ZUAZU, \\ J.M. REGOJO BALBOA, J.M. FERNÁNDEZ MONTERO, J. LÓPEZ FERRANDIS \\ J.E. ROBLES GARCÍA, J.J. ZUDAIRE BERGERA, J. GARCÍA FONCILLAS*, \\ J.M. BERIÁN POLO
}

Departamento de Urología. *Área de terapia celular. Clínica Universitaria. Universidad de Navarra. Pamplona.

\section{RESUMEN}

MUTACIONES DEL GEN DEL RECEPTOR DE ANDRÓGENOS EN PACIENTES CON ADENOCARCINOMA DE PRÓSTATA CLÍNICAMENTE LOCALIZADO

Los objetivos del presente trabajo son el estudio de las mutaciones del gen del receptor de andrógenos, tanto su frecuencia como su localización en pacientes sometidos a prostatectomía radical.

MATERIAL Y MÉTODOS: Se realizó la secuenciación genómica en 67 pacientes sometidos a prostatectomía radical. La edad media fue de 64 años. La mediana de PSA fue de $15 \mathrm{ng} / \mathrm{ml}$. El 34,3\% de los pacientes presentaban un estadio T1 y el 65,7\% un estadio T2.

Secuenciación genómica: 1. Desparafinación de las muestras. 2. Extracción del ADN genómico. 3. Amplificación del ADN. 4. Secuenciación. 5. Evaluación de la secuenciación con el GenBank.

RESULTADOS: Un 16,7\% de los pacientes presentaban mutaciones del gen del receptor de andrógenos. La mutación más frecuente fue la mutación puntual. El exón más frecuentemente mutado fue el exón 1.

PALABRAS CLAVE: Cáncer de próstata. Prostatectomía radical. Receptor de andrógenos. Gen del receptor de andrógenos. Secuenciación genómica.

\section{ABSTRACT}

HUMAN ANDROGEN RECEPTOR GENE MUTATIONS IN PATIENTS UIT CLINICALLY LOCALIZED PROSTATE CANCER

The aim of this study was to detect mutations in the human androgen receptor gene in radical prostatectomy specimens.

MATERIAL AND METHODS: The genomic sequence was realized in 67 radical prostatectomy specimens. The mean age was 64 years old. The PSA median was 15 ng/ml. TNM 1997: 34.3\% were T1 and $65.7 \% \mathrm{~T} 2$.

Genomic sequence: 1. Radical prostatectomy specimens desparaffitation. 2. Extraction of the DNA 3. DNA amplification. 4. Automatic genome sequence. 5. Comparison with Gene-Bank.

RESULTS: $16.7 \%$ of the specimens were mutated. The most frequent mutation was the puntual mutation. The exon most frecuent mutated was exon 1. 
L as hormonas esteroideas tienen mecanismos de acción mediados por sus receptores específicos, llamados receptor de andrógenos, estrógenos, progesterona, glucocorticoides y mineralcorticoides. Estos receptores son miembros de una superfamilia de receptores ${ }^{1}$.

$\mathrm{El}$ receptor de andrógenos pertenece a la superfamilia de los receptores de localización nuclear. Estos receptores son factores de transcripción ligando dependientes que regulan la expresión de genes diana uniéndose a elementos específicos del ADN.

El análisis de la secuencia de aminoácidos indica que los miembros de la superfamilia de los receptores nucleares presentan una estructura común, lo que hace pensar que su origen es un receptor común que ha evolucionado especializándose. Estos receptores se dividen en seis regiones de estructura primaria denominadas de la A a la F. Cada una de estas regiones puede contener uno o varios dominios funcionales.

El extremo N-terminal del receptor, contiene las regiones $\mathrm{A}$ y $\mathrm{B}$ que son altamente variables en su secuencia y longitud dependiendo de cada tipo de receptor. Estas regiones contienen los dominios de transactivación del $\mathrm{ADN}^{2}$.

La región $\mathrm{C}$ contiene el dominio de unión al $\mathrm{ADN}$ que es el dominio mejor conservado en todos los receptores. Las posiciones de los residuos de cistina se encuentran absolutamente conservadas en todos los receptores y en ellas se encuentran los puentes de zinc tipo II. Esto favorece el reconocimiento y define con exactitud la estructura de estos receptores. Muchos nuevos miembros de esta superfamilia se han identificado gracias a la presencia de esta estructura característica de la región $\mathrm{C}^{3}$. Los dos puentes de cinc presentan distintas funciones entre sí. El puente situado en la zona $\mathrm{N}$-terminal del receptor de andrógenos (AR) se une con una región del ADN que permite el ensamblaje del mismo con la secuencia de nucleótidos del HRE. El puente Cterminal se une con gran afinidad al $\mathrm{ADN}$, lo que provee al receptor de una columna de residuos fosfato que aumenta la unión del dominio de unión al ADN al HRE.

La región $\mathrm{D}$ se denomina también región bisagra. Es una zona de longitud muy variable y poco conservada entre los distintos receptores.
El extremo C-terminal del receptor contiene las regiones $\mathrm{E}$ y $\mathrm{F}$. La región $\mathrm{E}$ contiene dos zonas conservadas y comunes a todos los receptores nucleares. La función principal de esta región es su unión al ligando pero también mantiene funciones de transactivación del $\mathrm{ADN}^{4}$. Esta región, también contiene un dominio de dimerización con un fragmento rico en residuos de leucina ${ }^{5}$.

La región $\mathrm{F}$ sólo está presente en algunos receptores. En otros receptores como el receptor de estrógenos, la región $\mathrm{F}$ está presente pero su delección no provoca ninguna alteración funcional del mismo ${ }^{6}$. En el AR la región F está presente y regula la unión del receptor al ligando.

Existen distintas enfermedades, además del cáncer de próstata, en las que la mutación o el mal funcionamiento del AR están presentes. La más característica es el síndrome de insensibilidad a los andrógenos en los que el receptor presenta distintas alteraciones que provocan su mal funcionamiento en presencia de concentraciones normales de andrógenos circulantes (concentración normal de TST plasmática) y de un normal funcionamiento de la 5- $\alpha$-reductasa tipo 2 (presencia de DHT celular). La insensibilidad a los andrógenos puede ser completa o incompleta y se debe a mutaciones en el gen de receptor de andrógenos (hAR). Estas mutaciones son de tipo germinal y están presentes en todas las células del organismo, mientras que las mutaciones presentes en el cáncer de próstata son de tipo somático y sólo afectan al tejido prostático tumoral. El resto de enfermedades asociadas a mutaciones del gen hAR son síndromes neurológicos degenerativos como la enfermedad de Kennedy o la atrofia muscular bulbo-espinal.

El AR es una proteína de 919 amino-ácidos de longitud y con un peso molecular de 98 kilodaltons ${ }^{7}$. Como el resto de los receptores esteroideos, el AR tiene cuatro dominios funcionales.

En ausencia de ligando, el AR se encuentra unido a proteínas celulares que estabilizan su estructura terciaria y previenen su activación. La unión del AR con los andrógenos provoca una disociación de estas proteínas, fosforilación del $\mathrm{AR}$, interacción con los elementos de respuesta de los andrógenos y de forma final una activación de la trascripción de los genes regulados por los andrógenos. 
Uno de los pasos clave para el desarrollo de las funciones de estos receptores, es la interacción con el ADN. Los receptores nucleares modulan la transcripción reconociendo específicamente secuencias de nucleótidos denominados elementos de respuesta hormonal (HRE). La formación de dímeros de los receptores nucleares, va a condicionar la eficiencia de la unión del receptor a sus HRE. A través de estas secuencias (HRE), el AR activa los genes de respuesta androgénica como son el PSA o la kalicreina glandular humana tipo $2^{8}$.

El gen del receptor de andrógenos (hAR) se encuentra en el brazo largo del cromosoma X (qX 11-12). El hAR se divide en ocho exones con una longitud de 2730 pares de bases. La secuencia que codifica el dominio N-terminal se encuentra en el exón 1. El dominio de unión al ADN se codifica en los exones 2 y 3 . La región bisagra se codifica en el exón cuatro. El dominio C-terminal se distribuye en los exones 4 al 8.

El primer exón contiene dos repeticiones de trinucleótidos que codifican una secuencia poliglutamina y otra poliglicina. La secuencia de poliglutamida está codificada por el triplete CAG y la de poliglicina por el tracto GGN.

El número de repeticiones del triplete CAG varía en los individuos sanos entre 8 y 35 repeticiones. Un mayor número de repeticiones puede producir una disminución de la actividad trascripcional "in vivo" e "in vitro" 9 .

Existen otras patologías no tumorales relacionadas con la variabilidad de la repetición del triplete CAG. Cuando existen más de 40 repeticiones pueden aparecer alteraciones neurológicas como la atrofia bulbar espinal, también se relaciona con atrofia testicular y defectos de la virilización ${ }^{10}$.

El tracto GGN está constituido por tres repeticiones del triplete GGT, un triplete GGG, dos tripletes GGT y un número variable de repeticiones del triplete GGC $\left(\mathrm{GGT}_{3} \mathrm{GGG}_{1} \mathrm{GGGT}_{2} \mathrm{GGCn}\right)^{11}$. El polimorfismo del tracto GGN (un GGN corto) también puede aumentar el riesgo de padecer cáncer de próstata ${ }^{12}$.

\section{MATERIAL Y MÉTODOS}

El objetivo del presente trabajo es el estudio de las mutaciones del gen del receptor androgénico mediante secuenciación genómica, en pacientes diagnosticados de adenocarcinoma de próstata clínicamente localizado tratados mediante prostatectomía radical.

- Detección de la frecuencia de mutaciones del gen hAR.

- Localización y caracterización del tipo de mutaciones del gen hAR en el carcinoma de próstata humano.

\section{VARIABLES CLINICO-PATOLÓGICAS}

Se incluyen en el estudio 67 pacientes diagnosticados de adenocarcinoma de próstata clínicamente localizado, de los 165 tratados mediante prostatectomía radical con linfadenectomía iliobturatriz entre 1990 y 1997.

De las piezas de prostatectomía radical, y tras su estudio anatomopatológico, se obtuvieron muestras de tejido prostático a partir de los bloques de parafina en los que el estudio anatomopatológico demostraba la presencia de adenocarcinoma de próstata. Se obtuvieron de 5 a 10 cilindros de parafina con un peso aproximado de 10 miligramos. En el caso de no obtener suficiente tejido para la realización de la secuenciación completa del gen del receptor de andrógenos se obtuvieron más muestras del mismo bloque de parafina.

\section{Variables clínicas}

La edad media de los pacientes fue de 64 años (rango 52-77 años).

La sospecha de cáncer de próstata se realizó por la presencia de un aumento del PSA total plasmático en 21 pacientes $(31,3 \%)$, por tacto rectal anómalo en 2 pacientes (3\%) y por alteración del tacto rectal y elevación del PSA en 42 pacientes $(62,7 \%)$. En 2 pacientes el diagnóstico de cáncer de próstata se realizó de forma incidental tras la realización de RTU o adenomectomía retropúbica.

La mediana de PSA en el momento del diagnóstico fue de $15 \mathrm{ng} / \mathrm{ml}$ (media 24,24 ng/ml, rango $1-130 \mathrm{ng} / \mathrm{ml}$ ).

En todos los pacientes con sospecha de tumor prostático, el diagnóstico de cáncer de próstata se realizó mediante biopsia de próstata y su posterior estudio anatomo-patológico.

Siguiendo la clasificación TMN de la Internacional Unión Against Cancer (UICC) se codificaron todos los pacientes según la última revisión de 1997 (TNM 1997). 
Siguiendo esta clasificación, 23 pacientes $(34,3 \%)$ presentaban estadio clínico T1 y 44 (65,7\%) estadio T2.

Tras la realización de la biopsia, 54 (80,6\%) pacientes fueron clasificados según el grado histológico de Gleason. Nueve pacientes fueron clasificados como Gleason 2, 6 como Gleason 3, 11 como Gleason 4, 10 como Gleason 5, 8 como Gleason 6, 3 como Gleason 7, 5 como Gleason 8, 1 como Gleason 9 y 1 como Gleason 10.

\section{PROCESADO DE LAS MUESTRAS}

Algoritmo de trabajo

1. Desparafinación de las muestras.

2. Extracción del ADN genómico.

3. Amplificación del ADN.

A. Purificación de los productos de PCR.

4. Secuenciación.

A. Reacción de secuenciación mediante termociclación.

B. Purificación del producto resultante de la reacción de secuenciación con la eliminación de marcadores marcados mediante las columnas de CENTRISEP.

C. Gel de secuenciación.

i. Limpieza de los cristales de secuenciación.

ii. Preparación del gel.

D. Cargar las muestras en el gel de secuenciación.

E. Electroforesis durante un tiempo de 7 horas.

5. Evaluación de la secuenciación con el GenBank.

\subsection{Desparafinación del tejido}

- Añadir $25 \mathrm{mg}$ de tejido en un tubo de $2 \mathrm{ml}$ para microcentrifugado.

- AAñadir $1200 \mu \mathrm{L}$ de xyleno. Agitar.

- AAñadir $1200 \mu \mathrm{L}$ de etanol (96-100\%) para eliminar el xileno residual.

- Centrifugar 5 minutos.

- Eliminar el etanol.

- Repetir los tres últimos pasos una vez más.

\subsection{Extracción de ADN genómico}

Para la extracción de ADN del tejido propiamente dicho se empleó el kit GIAamp DNA Mini
Kit (50) de QIAGEN $^{\circledR}$, siguiendo las instrucciones del fabricante.

La concentración de ADN y su pureza se calcularon midiendo la absorbancia de luz UV a 260 $\mathrm{nm}$ y a $280 \mathrm{~nm}$ en un espectrofotómetro GENE QUANT-II RNA/DNA CALCULATOR (PharmaciaBiotech) ${ }^{\circledR}$.

La razón A260/A280 fue en todos los casos superior a 1.8

\subsection{Amplificación del ADN}

Debido a la enorme amplificación posible con el proceso $\mathrm{PCR}$, pequeños niveles de contaminación de $\mathrm{ADN}$, especialmente de reacciones de amplificación PCR previas, muestras con niveles altos de ADN, y moldes positivos de control, pueden resultar en formación de productos incluso en la ausencia de moldes de ADN añadidos intencionadamente. Todas las reacciones deberían ser realizadas en un área separada de los productos de análisis PCR. El uso de vasos, soluciones y pipetas desechables para preparación de ADN, reacciones de mezcla, y análisis de muestras minimizará la contaminación.

Las reacciones de PCR se llevaron a cabo en un volumen de $50 \mu \mathrm{l}$ con concentraciones de $\mathrm{MgCl}_{2} 2$ $\mathrm{mM}$, dNTP 0,2 mM, cebadores 0,8 mM, 0,05 unidades/ $\mu$ le Taq Gold $^{\circledR}$ (Applied Biosystems, ROCHE), $3 \mu \mathrm{l}$ de DMSO (dimetilsulfóxido) por reacción $\mathrm{y}$, aproximadamente $1 \mu \mathrm{g}$ de DNA genómico también por reacción. El fragmento final del exón 1 , que incluye una zona de repeticiones CGG, mostró una enorme dificultad para ser amplificado. Se recurrió a la utilización del reactivo "Perfect Match ${ }^{\circledR}$ PCR Enhancer” (Stratagene), $1 \mu$ por reacción.

Las condiciones de amplificación consistieron en un paso inicial de desnaturalización a $95^{\circ} \mathrm{C}$ durante 10 minutos, seguido por 40 ciclos de $95^{\circ}$ durante 1 minuto 30 segundos, $60^{\circ}$ durante un minuto y un último paso de polimerización de $72^{\circ}$ durante 2 minutos. Para los fragmentos 1c, $1 \mathrm{~d}$ y le se empleó una temperatura de realineamiento de $61^{\circ} \mathrm{C}$ en lugar de $60^{\circ}$. Los productos de PCR se comprobaron por electroforesis en gel de agarosa al $2 \%$ en TAE $1 \mathrm{X}$, teñido con bromuro de etidio a una concentración final de $0,5 \mu \mathrm{g} / \mathrm{ml}$. La electroforesis se realizó a $160 \mathrm{~W}$ durante 30 minutos. La lectura de los geles se realizó en un transiluminador de luz ultravioleta (Fig. 1). 


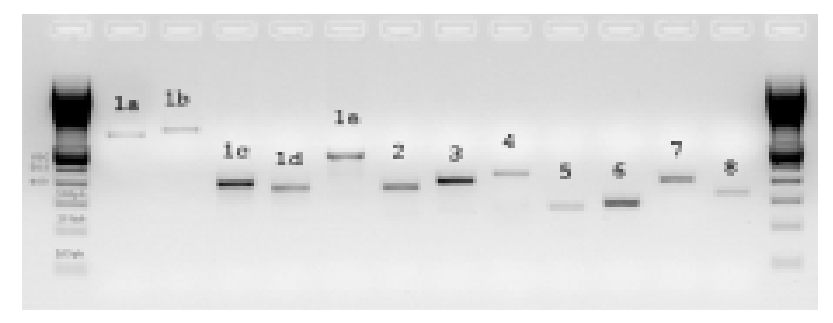

FIGURA 1. Electroforesis en gel de agarosa al $2 \%$ de los productos de PCR resultantes de la ampliación de las regiones codificantes del gen hAR.

Todas las reacciones se llevaron a cabo en un termociclador GeneAmp PCR System 2400 (Perkin-Almer) ${ }^{\circledR}$.

\subsection{Secuenciación}

Como cebadores para las reacciones de secuenciación se emplearon los mismos que para las amplificaciones pero a una concentración de 0,15 pmol/pl y el Kit de secuenciación "BigDye ${ }^{\circledR}$ Terminator Cycle Squencing Ready Reaction" (Applied Biosystems, ROCHE).

\section{A. Reacción de secuenciación mediante termo- ciclación}

Utilizamos el kit: DNA Sequencing Kit (№ ref: 4303152) de PE Biosystems.

Poner $1 \mu \mathrm{l}$ del producto de PCR purificado con una mezcla de:

- Terminator $=8 \mu \mathrm{l}$

- Primer $(3,2$ pmoles $)=1 \mu \mathrm{l}$

- $\mathrm{H}_{2} \mathrm{O}$ hasta llevar la reacción a $20 \mu \mathrm{l}(10 \mu \mathrm{l})$.

El programa utilizado es el siguiente:

$96 \%$ C . . . . . . . . 10 seg

$50^{\circ} \mathrm{C} \ldots \ldots \ldots .5 \mathrm{seg}$

$60^{\circ} \mathrm{C} \ldots \ldots .4 \mathrm{~min}$ 25 ciclos

$4^{\circ} \mathrm{C} \ldots \ldots \ldots$

B. Purificación del producto resultante de la reacción de secuenciación con la eliminación de marcadores mediante las columnas de CENTRISEP

Para la eliminación de los terminadores no incorporados se utilizaron las columnas de purificación "Centri-Sep Colums" ${ }^{\circledR}$ (Princeton Separations).

- El kit de CENTRISEP contiene tres componentes:
Tubos eppendorf: tubos de recolección de muestras. Capacidad de 1,5 ml.

Tubos de lavado: largos cilíndricos acabados en un cono. Capacidad de $2 \mathrm{ml}$.

Columnas CENTRISEP: tubos cónicos largos con capuchón en ambos extremos. Contienen el gel seco responsable de la purificación.

- El objetivo de este paso, radica en eliminar los terminadores marcados que no se han utilizado en la reacción evitando el reflejo de fluorescencia en el gel de secuenciación.

- Secar el producto al vacío a temperatura ambiente durante 25 minutos.

- Diluir el ADN de la parte inferior del eppendorf el buffer de carga.

\section{Gel de Secuenciación}

i. Limpieza de los cristales de secuenciación:

- Previamente a su uso, los cristales deben ser limpiados con agua y si es posible con solución alconox detergente.

- Secar los cristales con papel especial.

- En caso de aparecer manchas, limpiar con isopropanol al $70 \%$ y en su defecto metanol puro o etanol al $70 \%$.

ii. Preparación del gel

El gel de acrilamida necesario se elaboró a partir del reactivo "Prona Sec PRONAMATRIX 4.5” (Pronadisa):

Colocar los cristales y espaciadores en el cassette según el método descrito para el secuenciador.

Mezclar bien en un vaso de precipitados:

- $45 \mathrm{ml}$ Pronamatrix.

$-5 \mathrm{ml}$ TBE 10x.

El análisis de la secuencia se llevó a cabo empleando el secuenciador ABI 377 (ABI, PerkinElmer) mediante los softwares "Sequence Navigator 1.0.1" y "Sequence Análisis 3.4.1" (ABI PRISM, Applied Biosystems, Perkin-Elmer).

D. Cargar las muestras en el gel de secuenciación

- Para cargar la muestra es necesario preparar la suspensión de carga de secuenciación:

- $1 \mu \mathrm{l}$ de EDTA 0,5 mM.

- $20 \mu \mathrm{l}$ de azul de dextrano $(50 \mathrm{mg} / \mathrm{ml})$.

- Diluir el ADN seco en un volumen $4 \mu \mathrm{l}$ de la solución anterior. 
- Voltear las muestras adecuadamente.

- Dejar las muestras en hielo.

- Calentar las muestras durante tres minutos a $95^{\circ} \mathrm{C}$.

- Dejar las muestras en hielo.

- Cargar 0,6 pl en cada uno de los pocillos dejando entre dos muestras al menos un pocillo vacío (cargar las muestras alternativamente en los pocillos impares). Empleamos el peine de 64 calles y comenzamos por cargar sólo la mitad de las muestras. Correr el gel en electroforesis durante cinco minutos antes de cargar el resto de las muestras.

\section{E. Electroforesis del gel durante un tiempo de 7 horas}

2.5. Evaluación de la secuenciación con el GenBank.

El análisis de la secuencia se llevó a cabo empleando el secuenciador ABI 377 (ABI, Perkin-Elmer ${ }^{\circledR}$ ) mediante el software "Sequence Navigator 1.0.1".

Las secuencias obtenidas se compararon con la secuencia extraída del GenBank. Las diferencias entre la secuencia problema y la secuencia molde se cotejaron en la base de datos de mutaciones del gen hAR (The Androgen Receptor Gene Mutations Database World Wide Web Server. http://ww2.mcgill.ca/androgendb/). Cuando un cambio en la secuencia era confirmado por una nueva secuenciación del fragmento se anotó en la base de datos de resultados.

3. Secuencia de los cebadores utilizados y de los amplicones obtenidos.

Las secuencias de los cebadores (iniciadores) utilizados en este estudio así como de los amplicones obtenidos han sido extraídas del artículo original de Lubhan publicado en 1989, donde se describe la secuencia completa así como los oligonucleótidos más informativos para un correcto estudio del gen así como las condiciones y características de las reacciones. El exón uno, debido a su gran tamaño, requiere varios pares de cebadores. En concreto el fragmento final requirió el diseño de algunos cebadores nuevos para poder abarcar toda su secuencia, sobre todo el fragmento final, que incluye una zona de repeticiones CGG muy dificil de amplificar en este tipo de mues- tras (tejido en parafina). El diseño se llevó a cabo empleando el software "Primer Express ${ }^{\circledR}$ 1.5" (ABI PRISM, Applied Biosystems, Perkin-Elmer).

Como cebadores para las reacciones de secuenciación se emplearon los mismos que para las amplificaciones pero a una concentración de $0,15 \mathrm{pmol} / \mu \mathrm{l}$.

\section{ANÁLISIS ESTADÍSTICO}

En el análisis estadístico se utilizó un estudio de regresión logística binaria univariado y multivariado para la identificación de los factores influyentes en la progresión de la enfermedad. Las medias se han comparado mediante la prueba $\mathrm{T}$ para la comparación de medias. El coeficiente de correlación de Pearson se utilizó para la relación de variables cuantitativas. Análisis de supervivencia de Kaplan-Meier (con comparación de supervivencia de Log-Rank) y un análisis de regresión de Cox para la identificación de factores influyentes en la supervivencia.

\section{RESULTADOS}

Tras la realización del proceso de secuenciación, se demostró la presencia de alguna mutación en el gen del AR (hAR) en 11 pacientes $(16,4 \%)$ (Tabla I). En 56 pacientes $(83,6 \%)$ no existía ningún tipo de mutación.

$\mathrm{El}$ exón más frecuentemente afectado por las mutaciones fue el exón 1 con 5 mutaciones $(45,5 \%)$. En el exón 5 se observaron 2 mutaciones $(18,2 \%)$ y en los exones $4,6,7,8$ se observó una mutación $(9,1 \%)$ en cada uno.

Dentro del exón 1 se observó mutación en el codón 211 en tres casos (Fig. 2), en el codón 449 (Fig. 20) en un caso y en el codón 451 en otro caso.

El codón afectado en el exón 4 fue el 722 (Fig. 3).

Los codones afectados en el exón 5 fueron el 730 y el 747 .

El codón afectado en el exón 6 fue el 799.

El codón afectado en el exón 7 fue el 838 (Fig. 4).

El codón afectado en el exón 8 fue el 895.

El tipo de mutación más frecuentemente encontrada fue la mutación puntual que se observó en 10 casos $(90,9 \%)$, en un caso $(9,1 \%)$ la mutación encontrada fue una delección.

De las 10 mutaciones puntuales, 4 no provocan alteración del amino-ácido resultante mientras que las otras 6 sí modifican algún aminoácido de la estructura del AR. 
TABLA I

RESUMEN DE MUTACIONES ENCONTRADAS

\begin{tabular}{|c|c|c|c|c|c|c|}
\hline $\begin{array}{l}\text { Tipo de } \\
\text { mutación }\end{array}$ & $\begin{array}{c}\text { Exón } \\
\text { afectado }\end{array}$ & $\begin{array}{l}\text { Codón } \\
\text { afectado }\end{array}$ & aa inicial & aa final & $\begin{array}{c}\text { Nucleótido } \\
\text { inicial }\end{array}$ & $\begin{array}{l}\text { Nucleótido } \\
\text { final }\end{array}$ \\
\hline Delección & 5 & 747 & $\begin{array}{l}\text { Fenil- } \\
\text { alanina }\end{array}$ & Leucina & Timina & - \\
\hline $\begin{array}{l}\text { Mutación } \\
\text { puntual }\end{array}$ & 1 & 211 & $\begin{array}{c}\text { Ác. } \\
\text { glutámico }\end{array}$ & Ác. glutámico & Guanina & Adenina \\
\hline $\begin{array}{l}\text { Mutación } \\
\text { puntual }\end{array}$ & 1 & 449 & Glicina & Ác. aspártico & Guanina & Adenina \\
\hline $\begin{array}{l}\text { Mutación } \\
\text { puntual }\end{array}$ & 1 & 451 & Glicina & Ác. aspártico & Guanina & Adenina \\
\hline $\begin{array}{l}\text { Mutación } \\
\text { puntual }\end{array}$ & 1 & 211 & $\begin{array}{c}\text { Ác. } \\
\text { glutámico }\end{array}$ & Ác. glutámico & Guanina & Adenina \\
\hline $\begin{array}{l}\text { Mutación } \\
\text { puntual }\end{array}$ & 5 & 730 & Valina & Metionina & Guanina & Adenina \\
\hline $\begin{array}{l}\text { Mutación } \\
\text { puntual }\end{array}$ & 1 & 211 & $\begin{array}{c}\text { Ác. } \\
\text { glutámico }\end{array}$ & Ác. glutámico & Guanina & Adenina \\
\hline $\begin{array}{l}\text { Mutación } \\
\text { puntual }\end{array}$ & 6 & 799 & Isoleucina & Treonina & Timina & Citosina \\
\hline $\begin{array}{l}\text { Mutación } \\
\text { puntual }\end{array}$ & 7 & 838 & Leucina & Leucina & Citosina & Timina \\
\hline $\begin{array}{l}\text { Mutación } \\
\text { puntual }\end{array}$ & 4 & 722 & Leucina & Fenil-alanina & Guanina & Timina \\
\hline $\begin{array}{l}\text { Mutación } \\
\text { puntual }\end{array}$ & 8 & 895 & Metionina & Valina & Guanina & Adenina \\
\hline
\end{tabular}

\section{DISCUSION}

La mayoría de los carcinomas prostáticos responden al tratamiento hormonal ${ }^{13}$ mediante una disminución de la masa tumoral que se pone de manifiesto con una disminución del PSA plasmático, una mejoría objetiva en el número de lesiones metastásicas (principalmente lesiones óseas valoradas mediante gammagrafía ósea) y una mejoría clínica en pacientes con dolor óseo y/o sintomas obstructivos del tracto urinario.

Esta respuesta al tratamiento hormonal no es indefinida. A lo largo de su evolución, tarde o temprano, se va a producir una progresión de la enfermedad liberándose ésta del control hormonal. El periodo durante el cual el tumor prostático es controlado mediante manipulación hormonal, es muy variable y va a depender, entre otros factores, de la diferenciación celular del tumor, de la presencia de metástasis en el momento del diagnóstico y de la realización previa de algún tratamiento con intención curativa (cirugía radical o radioterapia). Los mecanismos por los cuales las células tumorales escapan al control androgénico y pasan a tener un crecimiento independiente de la estimulación hormonal no están suficientemente aclarados. Existen indicios que aportan distintos mecanismos moleculares por los que las células prostáticas tumorales escapan del control apoptótico que inicialmente produce la deprivación androgénica. En la mayoría de estos mecanismos de hormonorresistencia está implicado de forma directa o indirecta el AR. En algunos casos se ha postulado la presencia de forma inicial de clones de células hormonorresistentes junto con células hormonosensibles en el mismo tumor, produciéndose una selección de las primeras tras la deprivación androgénica. El 


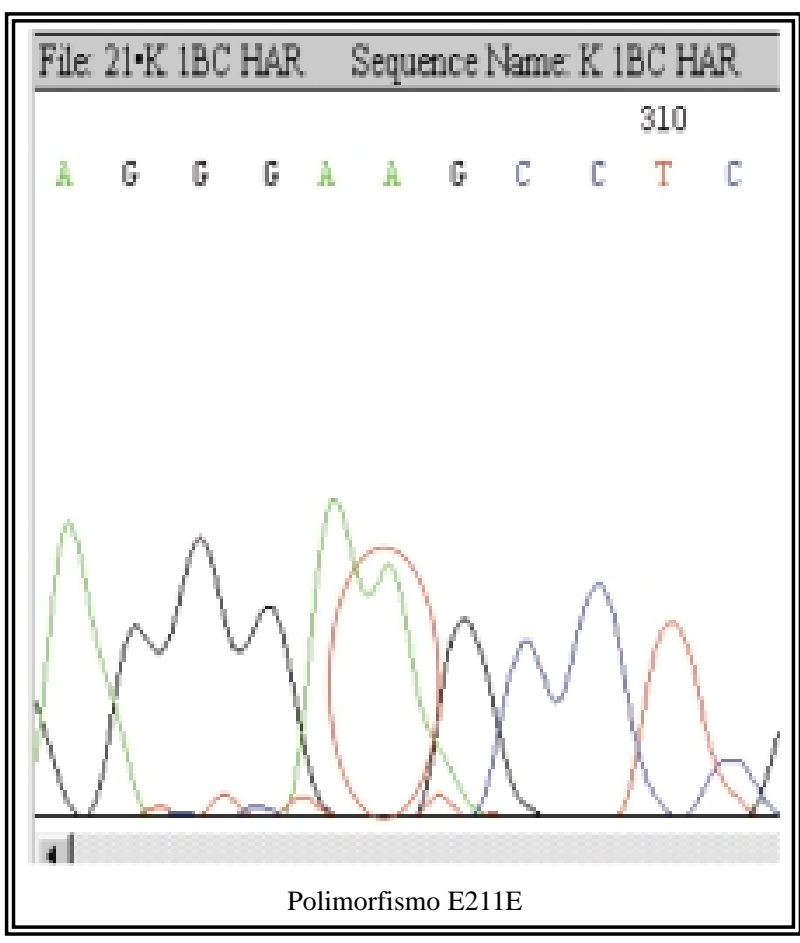

FIGURA 2. Polimorfismo en codón 211.

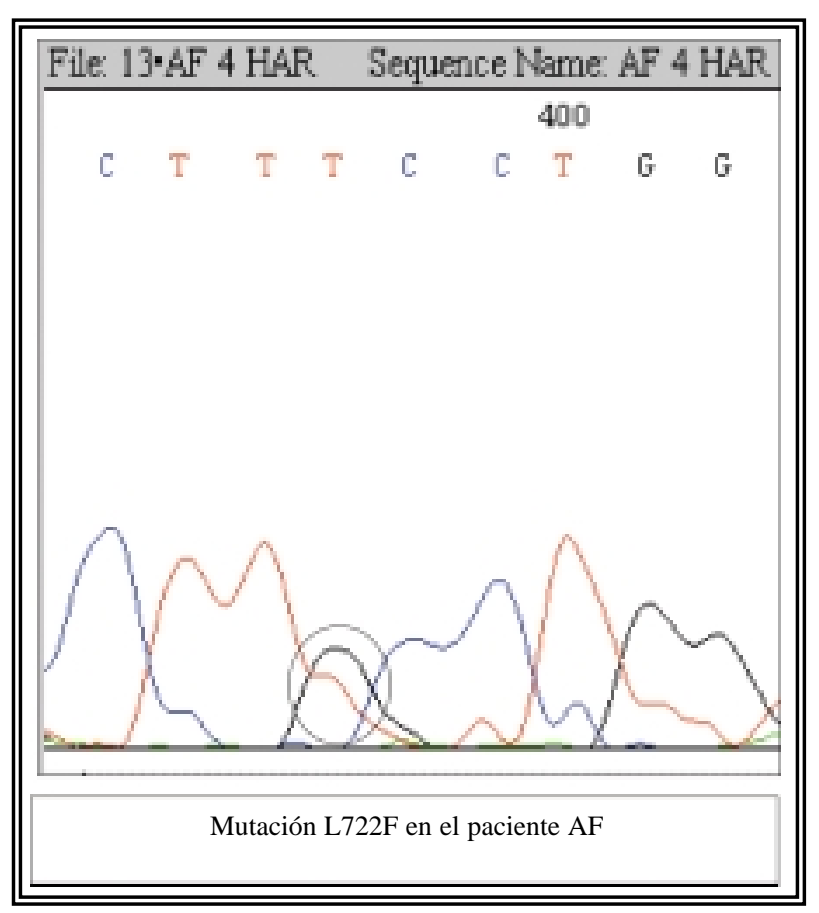

FIGURA 3. Mutación puntual en codón 722.

tiempo hasta la hormono-independencia vendría condicionado por el porcentaje inicial de células hormonorresistentes en el tumor primario. Otro posible mecanismo de producción de la hormonorresistencia sería la transformación de células

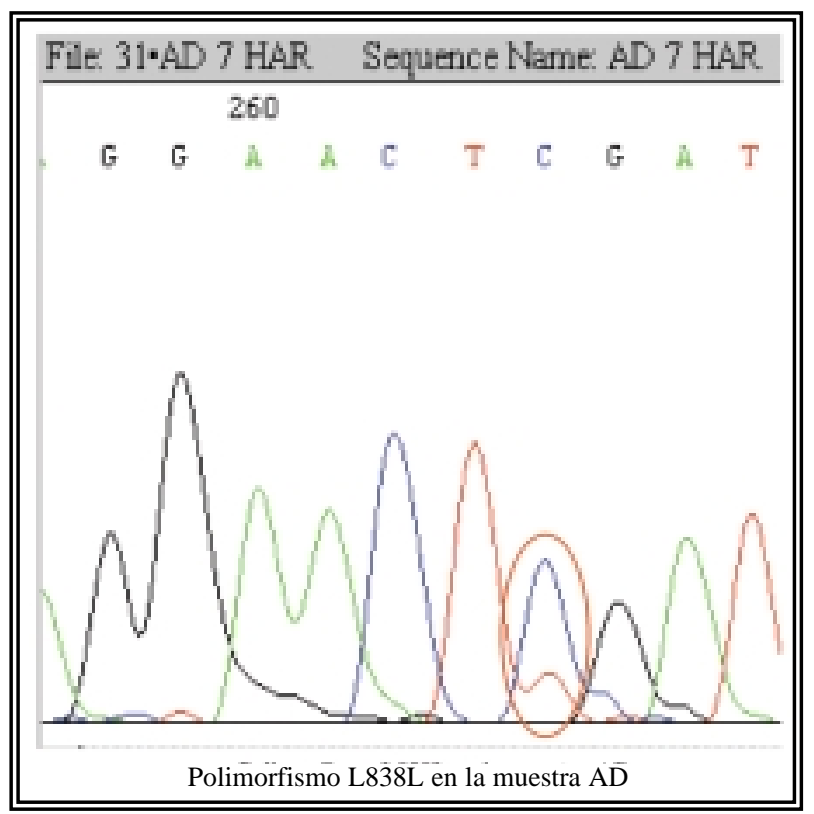

FIGURA 4. Polimorfismo en codón 838.

inicialmente hormonosensibles, en células hormonorresistentes gracias a modificaciones moleculares de las mismas. Dentro de estas modificaciones están la amplificación del AR, el aumento de sensibilidad del AR, aumento de la concentración de andrógenos a nivel prostático por un aumento de la expresión del enzima convertidor de la DHT, la aparición de mutaciones del AR y la activación del AR por ligandos no androgénicos.

En nuestro caso, pensamos que el segundo mecanismo sería el que más influye en la aparición de hormonorresistencia, ya que de las mutaciones encontradas en nuestros pacientes sólo una ha sido descrita anteriormente en pacientes con cáncer de próstata. Es la mutación en el codón 730 descrita por Newmark ${ }^{14}$ en pacientes con tumores prostáticos metastásicos. No existen estudios que valoren la presencia de mutaciones en tumores localizados y posteriormente en lesiones metastásicas en el mismo paciente, pero parece correcto pensar que conforme el tumor progresa va a desarrollar mutaciones que no presentaba anteriormente (variabilidad cuantitativa) y/o va a desarrollar mutaciones distintas a las que presentaba con anterioridad, modificando así la capacidad funcional del AR (variabilidad cualitativa).

El porcentaje de mutaciones en el hAR de pacientes con tumor localizado varía entre $0 \mathrm{y}$ $20 \%$, siendo la alteración genética más frecuente 
la presencia de mutaciones en el exón 1. En nuestro estudio, el porcentaje de pacientes con el hAR mutado es del $16,4 \%$, encontrando que la mayoría de las mutaciones se localizan en el exón 1 (5 mutaciones), seguido del exón 5 (dos mutaciones).

La frecuencia de mutaciones en tumores metastásicos es mayor que en tumores primarios, y en tumores hormonorresistentes mayor que la de tumores hormonosensibles ${ }^{15,16}$, por lo que se cree que estas mutaciones pueden jugar un papel importante en la progresión de la enfermedad ${ }^{17}$.

La presencia de mutaciones en el AR generalmente es consecuencia de mutaciones en el hAR. No todas las mutaciones en el hAR van a provocar alteraciones en el receptor ya que mutaciones puntuales en un codón pueden no alterar el amino-ácido resultante (polimorfismos) y por lo tanto no alterar la estructura proteica final. Sin embargo, estos polimorfismos deben tenerse en cuenta en el ámbito de una posible inestabilidad genética o fallo en los mecanismos de síntesis y reparación del $\mathrm{ADN}$ que puedan provocar alteraciones posteriores que implique una alteración en la morfología y/o funcional del AR. Esta inestabilidad genética, puede provocar la aparición de clones celulares genéticamente alterados cada uno con una expresión fenotípica distinta.

Además de la mutación descrita por Newmark, encontramos 8 tipos de mutaciones distintos que no han sido descritos previamente en pacientes diagnosticados de cáncer de próstata. De estas 8 mutaciones, 3 han sido descritas en pacientes con el síndrome de insensibilidad androgénica y 5 mutaciones no han sido descritas con anterioridad.

Las tres descritas en el síndrome de insensibilidad androgénica son las que se sitúan en los codones 211 (insensibilidad androgénica parcial), 722 (insensibilidad androgénica completa) y 838 (insensibilidad androgénica parcial).

La delección del codón 747 y las mutaciones puntuales de los codones 449, 451, 799 y 895 no han sido descritas ni en cáncer de próstata ni en el síndrome de insensibilidad androgénica. Existe una mutación descrita en el codón 895 descrita en el síndrome de insensibilidad androgénica, en la que el amino-ácido resultante es un residuo de treonina en vez de un residuo de valina, como en nuestro caso. El posterior estudio funcional "in vitro” de estas mutaciones así como la evolución de estos pacientes nos orientará respecto al carácter evolutivo de estas mutaciones, así como respecto a su capacidad de liberar al receptor androgénico de su control hormonal.

\section{REFERENCIAS}

1. BEATO M, TRUSS M, SCHUTZ G.: Steroid hormone receptors: many actors in search of a plot. Cell 1995; 83: 851-857.

2. SARTORIUS CA, MELVILLA LY, HOVLAND AR et al.: A tird transactivation function of human progesterone receptors located in the unique N-terminal segment of the B-isoform. Mol Endocrinol 1994; 8: 1347-1360

3. WANG LH, TSAI SY, COOK RG et al.: COUP transcription factor is a member of the steroid receptor superfamily. Nature 1989; 340: 163-166.

4. BANIAHMAD A, LENG X, BURRIS TP et al.: The T4 activation domain of the thyroid hormone receptor is required to realase a correpressor necessary for silencing. Mol Cell Biol 1995; 15: 76-86.

5. FARELL SE, LEES JA, WHITE R, PARKER MG.: Characterization and colocalization of steroid binding and dimerzation activities in the mouse estrogen receptor. Cell 1990; 60: 953-962.

6. KUMAR V, GREEN S, SNACK F et al.: Functional domains of the human estrogen receptor. Cell 1987; 51: 941-951.

7. TRAPMAN J, KLAASSEN P, KUIPER GG et al.: Cloning, structure and expression of a cDNA encoding the human androgen receptor. Biochem Biophys Res Commun 1988; 153: 241-248.

8. HABIB FK, GRANT ES.: Molecular and cellular biology of the prostate: is it clinically relevant? Br J Urol 1996; 78: 546-551.

9. CHOONG CS, KEMPPANIEN JA, ZHOU ZX, WILSON E.: Reduced androgen receptor gene expression with first exon CAG repeat expansion. Mol Endocrinol 1996; 10: 1527-1535.

10. NAGASHIMA T, SEKO HIROSE K et al.: Familiar bulbo-spinal muscula atrophy associated with testicular atrophy and sensory neuropathy: autopsy case report of two brothers. $J$ Neurol Sci 1988; 87: 141-152.

11. HSING AW, GAO YT, WU G et al.: Polymorphic CAG and GGN repeat leng in the androgen receptor gene and prostate cancer risk: a population based case control study in China. Cancer Res 2000; 60: 5111-5116.

12. STANFORD JL, JUST JJ, GIBAS M et al.: Polymorphic repeats in the androgen receptor gene: molecular markers of prostate cancer risk. Cancer Res 1997; 57: 1194-1198.

13. COFFEY R, WATSON RW, O'NEILL AJ, MCELENY K, FITZPATRICK JM.: Androgen mediated resistance to apoptosis. Prostate 2002; 53: 300-309.

14. NEWMARK JR, ARDÍ DO, TONB DC et al.: Androgen receptor gene mutations in human prostate cancer. Proc Natl Acad Sci. USA 1992; 89: 6319-6323.

15. EDER IE, CULIG Z, PUTZ T et al.: Molecular biology of the androgen receptor: from molecular understanding to the clinic. Eur Urol 2001; 40: 241-251.

16. MARCELLI M, ITTMANN M, MARIANI S et al.: Androgen receptor mutations in prostate cancer. Cancer Res 2000; 60: 944-949.

17. TILLEY WD, BUCHAMAN G, HICKEY TE, BENTEL JM.: Mutations in the androgen receptor gene are associated with progression of human prostate cancer to androgen independence. Clin Caner Res 1996; 2: 277-285.

Dr. D. Sánchez Zalabardo

Departamento de Urología. Clínica Universitaria

Pío XII, 36 - 31008 Pamplona (Navarra)

(Trabajo recibido el 4 noviembre 2003) 